\title{
Predicting Colonoscopy Completion Among African American and Latino/a Participants in a Patient Navigation Program
}

\author{
Debra J. Pelto • Jamilia R. Sly • Gary Winkel • \\ William Redd • Hayley S. Thompson • \\ Steven H. Itzkowitz • Lina Jandorf
}

Received: 17 April 2014 /Revised: 9 July 2014 / Accepted: 22 August 2014 /Published online: 11 September 2014

(C) W. Montague Cobb-NMA Health Institute 2014

\begin{abstract}
Patient navigation (PN) effectively increases screening colonoscopy (SC) rates, a key to reducing deaths from colorectal cancer (CRC). Ethnic minority populations have disproportionately low SC rates and high CRC mortality rates and, therefore, especially stand to benefit from PN. Adapting the Health Belief Model as an explanatory model, the current analysis examined predictors of SC rates in two randomized studies that used PN to increase SC among 411 African American and 461 Latino/a patients at a large urban medical center. Speaking Spanish but not English (odds ratio (OR), 2.192; $p<0.005$ ), having a higher income (OR, 1.218;
\end{abstract}

D. J. Pelto $(\bowtie) \cdot$ J. R. Sly $\cdot$ G. Winkel $\cdot$ W. Redd $\cdot$ S. H. Itzkowitz $\cdot$

L. Jandorf

Program for Cancer Prevention and Control, Department of

Oncological Sciences, Icahn School of Medicine at Mount Sinai, One

Gustave L. Levy Place, Box 1130, New York, NY 10029, USA

e-mail: debra.pelto@mssm.edu

J. R. Sly

e-mail: jamilia.sly@mssm.edu

G. Winkel

e-mail: gary.winkel@mssm.edu

W. Redd

e-mail: william.redd@mssm.edu

S. H. Itzkowitz

e-mail: steven.itzkowitz@mountsinai.org

L. Jandorf

e-mail: lina.jandorf@mssm.edu

\section{H. S. Thompson}

Department of Oncology, Population Studies and Disparities

Research Program, Karmanos Cancer Institute, Wayne State

University Medical Center, Detroit, MI 48201, USA

e-mail: thompsoh@karmanos.org

\section{S. H. Itzkowitz}

Division of Gastroenterology, Department of Medicine, Icahn School of Medicine at Mount Sinai, One Gustave L. Levy Place, Box 1069, New York, NY 10029, USA $p<0.005)$, and scoring higher on the Pros of Colonoscopy scale (OR, 1.535; $p=0.023)$ independently predicted colonoscopy completion. Health education and PN programs that increase awareness of the benefits of getting a colonoscopy may encourage colonoscopy completion. In the context of language-appropriate PN programs for African American and Latino/a individuals, those with lower incomes and English speakers may require additional education and counseling to support their decision-making around colonoscopy.

Keywords Colonoscopy · Cancer screening · Patient navigation · African Americans · Latinos · Ethnic minorities

Mathematics Subject Classification Codes $62 \mathrm{H} 15$ (statistics-multivariate analysis-hypothesis testing) $\cdot 62 \mathrm{P} 10$ (statistics-applications to biology and medical sciences) 62P25 (statistics-applications to social sciences)

\section{Introduction}

Colorectal cancer (CRC) is the second leading cause of death from cancer in the USA among women and men of all races [1]. Many of these illnesses and deaths are preventable, since the removal of precancerous polyps can reduce $\mathrm{CRC}$ incidence by 75-90\% [2]. The current national screening guidelines recommend performing either an annual fecal occult blood test, both sigmoidoscopy every five years and an annual blood stool test, or colonoscopy every ten years [3]. Of these screening methods, screening colonoscopy (SC) has been increasingly used because, unlike other methods, it allows detection and removal of precancerous polyps during a single procedure thereby preventing and, in some cases, even treating CRC [4]. While overall screening levels utilizing any of the 
three methods have risen to $65.1 \%$ in 2012 , they are still below the Healthy People 2020 goal of $70.5 \%$ and disparities persist among population subgroups [5-8]. Screening is lower among racial and ethnic minorities, those with low incomes, those with public health insurance, and the uninsured. Data collected during the 2010 National Health Interview Survey (NHIS), the most recent data available on national estimates of SC within the past ten years, revealed that, among persons ages 50 to $75,55.4 \%$ of whites had had a colonoscopy within the past ten years, compared with only $52.4 \%$ of African Americans and $44.8 \%$ of Latinos/as of any race [9].

In New York State (NYS), the 2010 Behavioral Risk Factor Surveillance System (BRFSS; the most recent data available) surveyed 4,487 New Yorkers by telephone on rates of having either a blood stool test in the past year or a sigmoidoscopy or colonoscopy in the past ten years [10]. Among NYS households with landlines, white and African American CRC screening rates were nearly the same, at an estimated 70.3 and $70.2 \%$, while Latino rates were $63.9 \%$. The insured had been screened at a rate of $71.5 \%$ and the uninsured at $40.6 \%$. Those who had not completed high school were screened at a rate of $55.7 \%$ compared with $74.2 \%$ in those with a college degree. Rates at the lower and upper levels of annual household income were $56.6 \%$ for under $\$ 15,000,57.5 \%$ for $\$ 50,000-\$ 74,999$, and $74.8 \%$ for over $\$ 75,000$. Median household income in NYS for 2008-2012 was estimated at $\$ 57,683$ [11]. It is worth noting that telephone surveys may not accurately estimate screening in lower income households. The increase in use of cell phones has been accompanied by a decrease in the use of landlines such that, in 2011, only $54.9 \%$ of households below the poverty level had a landline compared with $73.3 \%$ for households at or above the poverty level [12]. Overall however, while screening rates among higher income groups and among whites are improving, screening disparities remain among minority ethnicity groups and among those with lower incomes, lower educational levels, public health insurance, and a lack of health insurance.

It is crucial to address screening disparities because the underscreened are less likely to be diagnosed with local disease when treatment is most likely to be successful. For example, in the period 1999-2006, while $42 \%$ of CRC diagnoses among non-Hispanic white (NHW) men and $40 \%$ among NHW women was staged as local disease, only $36 \%$ of diagnoses among African Americans and $37 \%$ of diagnoses among Hispanics were localized. Of CRC diagnoses among NHW men and women, $19 \%$ were staged as distant disease compared with $25 \%$ among African American men, $24 \%$ among African American women, $22 \%$ among Hispanic men, and $21 \%$ among Hispanic women [13].
Patient navigation (PN), initially developed to assist patients with a new diagnosis of cancer to gain timely access to treatment, has been demonstrated to effectively increase uptake of colonoscopy screening among asymptomatic patients without high risk factors for $\mathrm{CRC}$ by addressing barriers to completion [14-16]. It has been found that the introduction of $\mathrm{PN}$, use of bilingual navigators, direct referral to endoscopy from primary care providers, and enhancements to the gastrointestinal suite (e.g., additional equipment, streamlining equipment cleaning processes to reduce waiting times, and redesign of the recovery area, thereby creating efficiency and allowing the allocation of more nursing staff from the recovery area to the procedure rooms) are associated with an increase in total colonoscopies and a decrease in broken SC appointments $[14,16]$.

In the present study, we explore factors that predict completion of SC. Our group previously reported on analyses of data components from research primarily aiming to examine the impact of different types of PN (navigation by peers or professionals; culturally targeted navigation) on colonoscopy adherence among ethnic minorities [17, 18]. For both the African American and Latino cohorts, all forms of PN were equally beneficial. This finding allows us to combine the full data set (for the current substudy) without regard to the study arm. Therefore, herein we examine predictors of colonoscopy in the entire sample exploring both sociodemographic (including race/ethnicity) and psychosocial (e.g., perceived risk, pros and cons of colonoscopy, self-efficacy, and knowledge) variables.

Researchers in the USA have previously reported that demographic factors (i.e., age, education, income, gender, and ethnicity); language (i.e., speaking Spanish but not English); intrapersonal barriers, such as lack of perceived risk, fear of pain, concerns about modesty, and bowel preparation; and logistical barriers such as scheduling challenges and long waiting times and cost (including high out of pocket costs among the insured) are associated with SC completion [19-22]. Therefore, patient-related demographic and psychosocial factors are important to consider in targeting, designing, and enhancing PN interventions. This post-hoc analysis adapted the Health Belief Model (HBM) as an explanatory model in examining baseline predictors of colonoscopy. The HBM has been used extensively as a model for cancer screening, including for CRC screening and colonoscopy [23-28]. The key constructs of the HBM as adapted for the current study are perceived susceptibility, perceived benefits, perceived barriers, self-efficacy, and knowledge. Psychosocial constructs included in this analysis were perceived risk for CRC, pros of colonoscopy, cons of colonoscopy, fear of colonoscopy, self-efficacy, and knowledge. The model additionally specifies that sociodemographic variables are modifying, but not necessarily statistically moderating, factors (see Fig. 1). 
Fig. 1 Adapted Health Belief Model

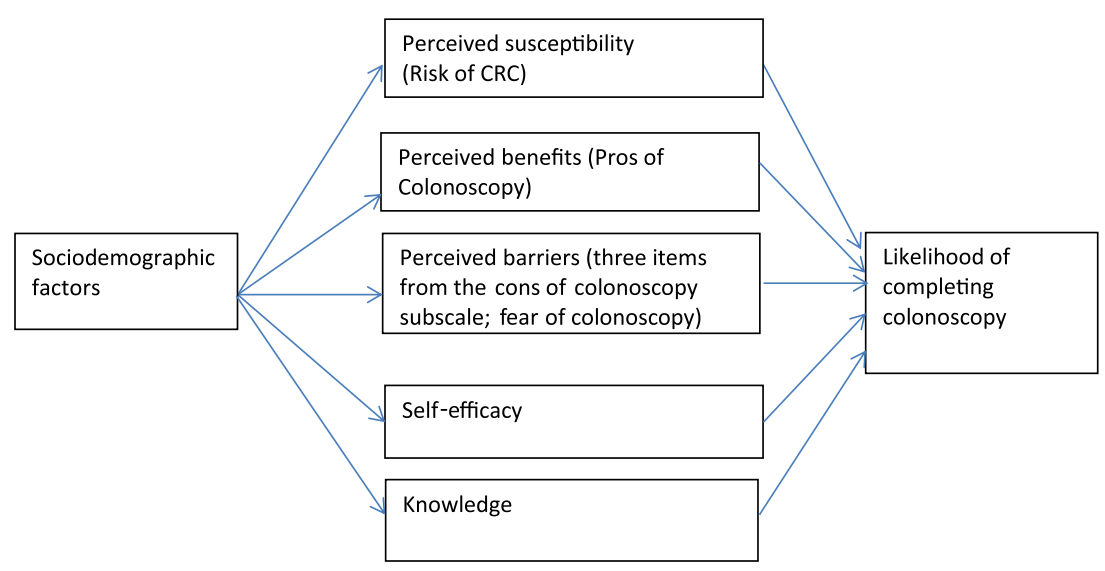

Methods

Study Setting and Recruitment

This study involves a secondary analysis of data from two IRB-approved, prospective PN cohort studies [15, 18]. In these studies, patients referred for SC by their primary care physician (PCP) at a non-acute medical visit were recruited at The Mount Sinai Hospital's primary care clinic between May 2008 and December 2011. SCs were ordered via an electronic medical record in which the criteria for screening were delineated. Research assistants were stationed in the clinic and worked directly with medical assistants to ensure recruitment of eligible patients. Interested patients met with the research assistant to discuss the study further and to sign informed consent if they were interested in participating and receiving navigation services. The assessment questionnaire was administered during this meeting after consent was obtained. ${ }^{1}$

African American and Latino/a patients 50 years of age or older without active gastrointestinal symptoms, significant comorbidities, or a history of inflammatory bowel disease or $\mathrm{CRC}$ were the groups of interest due to their low screening rates and because we were recruiting people at average risk for CRC. (Patients of other ethnicities were permitted to enroll and receive navigation. The data from these patients $(n=82)$ are not included in this analysis, since they were not members of the groups we were trying to reach and because their numbers were too small to allow statistical validity.) Participants must not have undergone SC for at least five years (an interval based on clinical practice at our institution) or have been up to date with other forms of CRC screening (e.g., FOBT or flexible sigmoidoscopy).

\footnotetext{
${ }^{1}$ A grant from the American Cancer Society covered copayments for those patients covered by Medicare who said they would have difficulty paying the copayment for the colonoscopy procedure and covered the cost of the colonoscopy procedure for the seven uninsured participants.
}

Enrollment

After recruitment, referrals were reviewed by nurses in the Division of Gastroenterology (GI) via electronic medical record to confirm medical eligibility and evaluate for contraindications to colonoscopy or sedation. In all, 1,212 African American and Latino/a patients were referred to the study. Of these, $90.9 \%(1,102)$ consented and enrolled. Upon review, $26(2.4 \%)$ of the 1,102 enrolled patients should not have been included in enrollment as they did not meet eligibility requirements (e.g., no working phone) and one was mistakenly enrolled twice; thus, they were not randomized. During the medical clearance process by the GI nurses, $204(19.0 \%)$ patients were determined ineligible for direct referral based on a medical condition (e.g., uncontrolled diabetes or hypertension, substance abuse, etc.) and, therefore, were not included in randomization. In addition, before randomization, three people withdrew and two had died (Fig. 2).

\section{Study Procedures}

The randomization procedures and study arm protocols have been previously described [17, 18]. All participants received three scripted telephone calls: a scheduling call, a call two weeks before the colonoscopy, and a final call three days before the procedure. After the first call, written instructions for bowel preparation and a reminder postcard with the colonoscopy date were mailed. The two reminder navigation calls included a review of preparation instructions, assessment of transportation needs, and the navigators provided education and support. Ten percent of recorded calls were monitored to ensure fidelity with each condition. In addition to the scheduling calls, a 30-min assessment interview was completed at the time of enrollment for which participants were compensated with \$20. A navigator was assigned according to the language 
Fig. 2 Schema of African American and Latino referral and enrollment

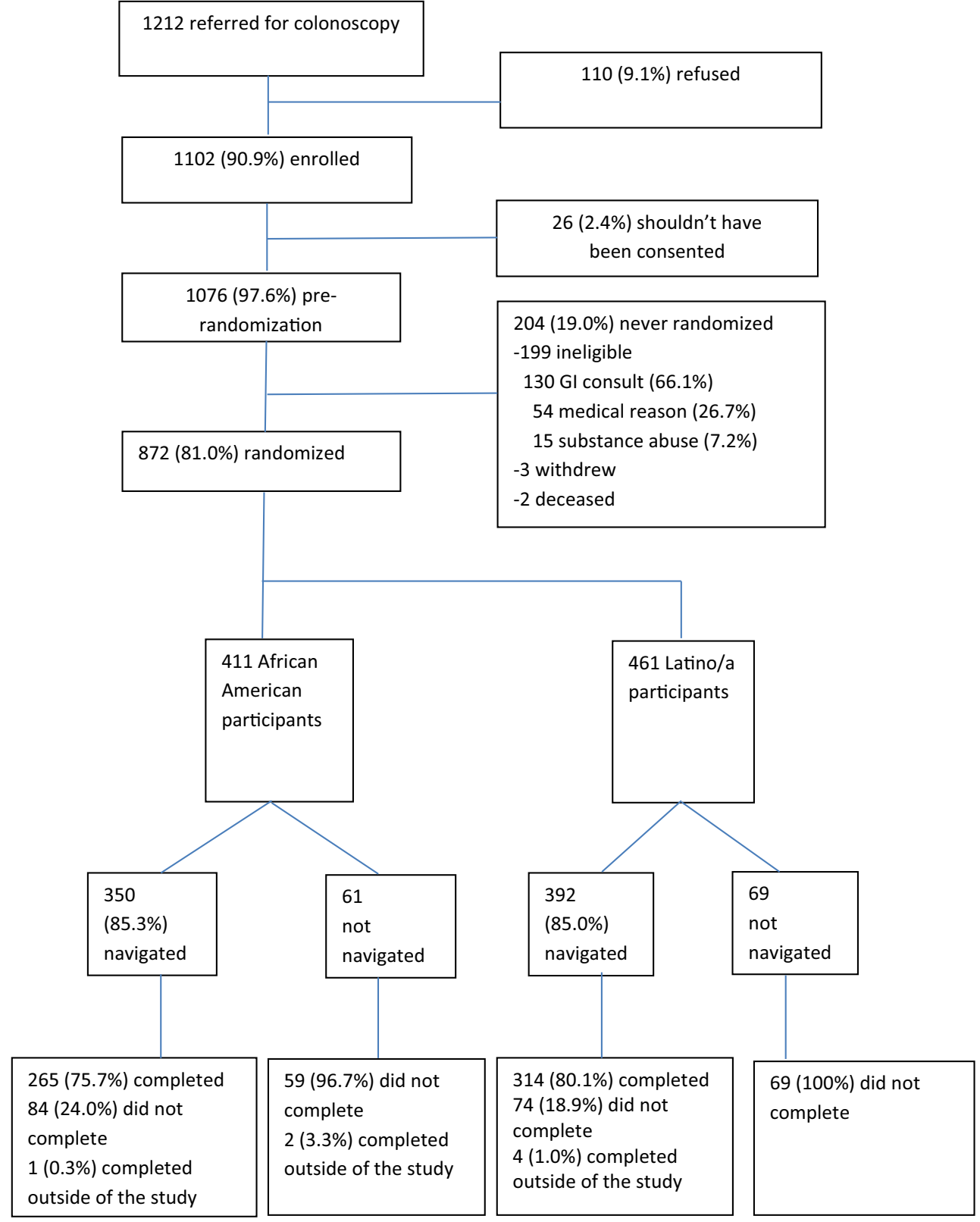

participants chose during their assessment: English, Spanish, or both languages. Those who were categorized as "both" included participants who initially said they were bilingual and those who had the original assessment in English but preferred to receive navigation in Spanish. Of the 872 randomized participants, 130 (14.9\%) were never reached for the first PN call resulting in 742 participants (350 African Americans and 392 Latinos/as) who received navigation. There was no significant difference in outcome between the two ethnic groups: the overall completion rates were $81.1 \%$ for the Latino/a participants and $76.0 \%$ for African American participants $(p=0.089)$. Thus, the two samples were aggregated for this analysis.
Measures

These data are based on the questionnaire administered at enrollment which included sociodemographic variables and several psychosocial measures previously reported as associated with CRC or other cancer screening, the use of which in these two studies has been previously described [17, 18]. Those included in this analysis are the following.

\section{Measures Related to HBM-Modifying Factors}

Participants were asked questions about their sociodemographic backgrounds, including age, gender, race 
and ethnicity, education, income, preferred language, country of birth, and insurance type (Table 1). Unless otherwise indicated, all analyses were conducted using SPSS 19.0.

\section{Measures Related to Key HBM Constructs}

The present analysis used three questions drawn from the 2005 Health Information National Trends Survey (HINTS) [29] to represent the HBM construct of perceived susceptibility. The response format varied from three to five points on a Likert-like scale. For example, participants were asked, "How likely do you think it is that you will develop colorectal cancer in the future?" with five choices ranging from "very low" to "somewhat high." These items were analyzed individually (see Table 2 for bivariate descriptive results).

For the HBM construct perceived benefits, a reduced version of the pros subscale of the Pros and Cons Index [30] was employed retaining three of the original nine items asking how strongly participants agreed or disagreed (on a 5-point Likerttype scale) with statements about the pros of having a colonoscopy (e.g., "A colonoscopy can find growths that are not yet cancer but could become cancer."). A mean value of the scores was calculated. See Table 2 for reliability analysis.

For the HBM key construct perceived barriers, two measures were employed: three items from the cons of colonoscopy subscale, and fear of colonoscopy. We retained three of the original seventeen items of the cons subscale from the Pros and Cons Index [30]. These items asked how strongly participants agreed or disagreed (on a 5-point Likert-type scale) with statements about the cons of having a colonoscopy (e.g., "I would probably not have a colonoscopy if I had to have laxatives."). There are six items in the previously published fear of colonoscopy Likert-type scale [31]. On a scale of one to five, participants were asked to rate how fearful they felt about issues related to colonoscopy (including the procedure, the preparation, etc.). For each of these measures representing perceived barriers, a mean value of the scores was calculated. See Table 2 for reliability analysis.

The present analysis used the measure self-efficacy regarding CRC for the HBM construct self-efficacy. These ten items (e.g., "I can arrange other things in my life to have a colonoscopy.") on a 5-point Likert-like scale were adapted from the self-efficacy scale for mammography [32]. See Table 2 for reliability analysis.

Knowledge This scale consists of ten true or false items measuring knowledge about CRC and the benefits of screening (e.g., "Even if colorectal cancer is found early, it probably cannot be cured.") abbreviated from the original 15 -item scale to reduce the length of the assessment [30]. See Table 2 for reliability scores.

\section{Analysis}

\section{Sociodemographic Characteristics}

The mean age of the study participants was 59.16 years (see Table 1). Of the 742 participants considered in this analysis, $516(69.5 \%)$ were female. In terms of race/ethnicity, the sample was close to evenly divided: $350(47.2 \%)$ were African American and 392 (52.8 \%) were Latino/a. Nearly three fourths $(73.2 \%)$ were not living with a partner. Fewer than half $(43.0 \%)$ had completed high school. Household income ranged from under $\$ 10,000(47.5 \%)$ to more than $\$ 50,000(6.1 \%)$. Nearly three fourths $(70.2 \%)$ were unemployed. The participants predominantly had public insurance (i.e., Medicaid or Medicare, $82 \%$ ), while the remainder had private insurance $(17.1 \%)$ or were uninsured $(0.9 \%)$. Over half $(52.8 \%)$ of the participants were born on the US mainland, nearly a quarter $(23.9 \%)$ were born in Puerto Rico $(n=$ $176)$ or the US Virgin Islands $(n=1)$, and nearly a quarter $(23.3 \%)$ were born in another country. Over two thirds preferred to speak English (68.3\%), nearly a third (30.1\%) preferred to speak Spanish, and 12 participants $(1.6 \%)$ were comfortable in both languages.

Sociodemographic Factors, Key HBM Constructs, and Colonoscopy Completion Drawing from the HBM as a theoretical explanatory model, we first tested whether sociodemographic factors, which are posited in the HBM as modifying variables, and the measures representing the key HBM constructs (perceived risk, benefits, barriers, self-efficacy, and knowledge) differed on the dichotomized outcome variable of colonoscopy completion versus non-completion. Because approximately $12 \%$ of the responses were missing on the original household income variable, missing values were imputed using the SAS procedure (MI) for multiple imputation of missing data. The mean and standard deviation of age can be found in Table 1. A point-biserial correlation was used to determine if age was associated with screening completion. Equality of proportions for all other sociodemographic variables was compared using a Chi-square test (Table 1). There were statistically significant differences between those who completed $(n=584)$ and did not complete a colonoscopy $(n=$ 158 ) on the variables for marital status and employment (each $p<0.050$ ) and for type of insurance, household income, origin, and language (each $p<0.005$ ). There was a marginally significant difference for race $(p=0.089)$. There was no significant difference for age $(p=0.139)$, gender $(p=0.827)$, or education $(p=0.592)$. To explore the differences between those participants who completed and did not complete a colonoscopy for the variables representing HBM key constructs, first, analyses were performed to ensure there was no violation of the assumptions of normality among the psychosocial measures, scales, and subscales of interest. Once 
Table 1 Sociodemographic variables and relationships with colonoscopy completion

\begin{tabular}{|c|c|c|c|c|c|c|}
\hline Covariates & Number $(N)$ & & & & & Colonoscopy \\
\hline & & Mean & SD & & & $p^{\mathrm{a}}$ \\
\hline \multirow[t]{3}{*}{ Age } & 742 & 59.160 & 7.511 & & & 0.139 \\
\hline & & \multicolumn{2}{|c|}{ Completed Colonoscopy } & \multicolumn{2}{|c|}{ Did not complete colonoscopy } & $p^{\mathrm{b}}$ \\
\hline & & $\mathrm{N}$ & $\%$ & $\mathrm{~N}$ & $\%$ & \\
\hline Gender & 742 & & & & & 0.827 \\
\hline Male & & 179 & 79.2 & 47 & 20.8 & \\
\hline Female & & 405 & 78.5 & 111 & 21.5 & \\
\hline Race/ethnicity & 742 & & & & & 0.089 \\
\hline African American & & 266 & 76.0 & 84 & 24.0 & \\
\hline Latino & & 318 & 81.1 & 74 & 18.9 & \\
\hline Marital status & 742 & & & & & 0.021 \\
\hline Living with a partner & & 168 & 84.4 & 31 & 15.6 & \\
\hline Not living with a partner & & 416 & 76.6 & 127 & 23.4 & \\
\hline Education & 737 & & & & & 0.592 \\
\hline Less than HS & & 252 & 79.5 & 65 & 20.5 & \\
\hline HS grad or more & & 327 & 77.9 & 93 & 22.1 & \\
\hline Income imputed & 740 & & & & & 0.000 \\
\hline$<10 \mathrm{~K}$ & & 236 & 72.8 & 88 & 27.2 & \\
\hline $10-14,999 \mathrm{~K}$ & & 120 & 85.7 & 20 & 14.3 & \\
\hline $15-19,999 \mathrm{~K}$ & & 43 & 68.3 & 20 & 31.7 & \\
\hline $20-24,999 \mathrm{~K}$ & & 35 & 74.5 & 12 & 25.5 & \\
\hline $25-29,999 \mathrm{~K}$ & & 36 & 87.8 & 5 & 12.2 & \\
\hline $30-39,999 \mathrm{~K}$ & & 56 & 90.3 & 6 & 9.7 & \\
\hline $40-49,999 \mathrm{~K}$ & & 21 & 91.3 & 2 & 8.7 & \\
\hline$\geq 50 \mathrm{~K}$ & & 35 & 87.5 & 5 & 12.5 & \\
\hline Employment status & 739 & & & & & 0.012 \\
\hline Employed & & 186 & 84.5 & 34 & 15.5 & \\
\hline Unemployed & & 396 & 76.3 & 123 & 23.7 & \\
\hline Type of insurance & 739 & & & & & 0.002 \\
\hline Public and self-pay & & 470 & 76.7 & 143 & 23.3 & \\
\hline Private & & 112 & 88.9 & 14 & 11.1 & \\
\hline Origin & 741 & & & & & 0.004 \\
\hline US mainland & & 290 & 74.2 & 101 & 25.8 & \\
\hline Puerto Rico or US Virgin Islands & & 144 & 81.4 & 33 & 18.8 & \\
\hline Foreign born & & 149 & 86.1 & 24 & 13.9 & \\
\hline Language & 742 & & & & & 0.001 \\
\hline Monolingual English and bilingual & & 392 & 75.5 & 127 & 24.5 & \\
\hline Monolingual Spanish & & 192 & 86.1 & 31 & 13.9 & \\
\hline
\end{tabular}

${ }^{\text {a }}$ Significance was computed using the correlation procedure

${ }^{\mathrm{b}}$ Significance was computed using the Chi-square statistic

again, a point-biserial correlation between completion/noncompletion and the HBM constructs and their associated significance levels and reliability was calculated for the scales. Four measures were found to have significance levels lower than 0.200: one question representing the key HBM construct perceived susceptibility (Compared with the average man/woman your age, would you say you are more/about as/less likely to develop colorectal cancer?) $(p=0.121)$; the pros of colonoscopy scale, representing the key HBM construct benefits $(p=0.008)$; the fear of colonoscopy scale, representing the key construct fear $(p=0.042)$; and the self-efficacy scale, 
Table 2 Knowledge and psychosocial measures as predictors of screening completion

\begin{tabular}{|c|c|c|c|c|c|}
\hline Scale/item & Mean (SD) & $\begin{array}{l}\text { Pearson } \\
\text { correlation }\end{array}$ & $p^{\mathrm{a}}$ & Number & $\begin{array}{l}\text { Cronbach's } \\
\text { alpha }\end{array}$ \\
\hline Knowledge regarding CRC & $0.731(0.215)$ & -0.027 & 0.464 & 739 & 0.368 \\
\hline $\begin{array}{l}\text { How likely do you think it is that you will develop } \\
\text { colorectal cancer in the future? }\end{array}$ & $2.060(1.082)$ & 0.037 & 0.330 & 680 & $\mathrm{n} / \mathrm{a}$ \\
\hline $\begin{array}{l}\text { Compared with the average man/woman your age, would you say you } \\
\text { are more/about as/less likely to develop colorectal cancer? }\end{array}$ & $1.793(0.711)$ & 0.059 & 0.121 & 692 & $\mathrm{n} / \mathrm{a}$ \\
\hline How often do you worry about getting colorectal cancer? & $1.410(0.702)$ & 0.038 & 0.305 & 736 & $\mathrm{n} / \mathrm{a}$ \\
\hline Self-efficacy regarding CRC screening & $4.232(0.527)$ & 0.107 & 0.004 & 714 & 0.871 \\
\hline Pros and cons index (pros subscale) & $4.164(0.490)$ & 0.098 & 0.008 & 738 & 0.471 \\
\hline Pros and cons index (cons subscale) & $2.049(0.572)$ & -0.039 & 0.285 & 739 & 0.511 \\
\hline Fear of colonoscopy scale & $2.005(0.947)$ & -0.075 & 0.042 & 738 & 0.848 \\
\hline
\end{tabular}

${ }^{\mathrm{a}}$ Significance was computed using the correlation procedure

representing the construct self-efficacy $(p=0.004)$. There was no significant difference between those who completed and did not complete a colonoscopy for the variables knowledge $(p=0.464)$ or for cons of colonoscopy ( $p=$ 0.285 ).

To find the predictors of completion among the sociodemographic variables, those with a Chi-square or $p$ value at the significance level of 0.200 or lower were entered into a logistic regression procedure and were sequentially eliminated based on significance values. After removing non-significant predictors, language (being monolingual Spanish) and income (having a higher income) were both significant predictors of completion at the levels of $p<0.005$. To examine how the four predictors of completion among the variables representing the key HBM constructs with differences at a significance level of $p=0.200$ or lower (perceived risk, pros of colonoscopy, fear of colonoscopy, and selfefficacy) serve as predictors in the context of a model including the two sociodemographic variables (income and language), four single-step logistic regression procedures were performed with the two demographic variables and each of the four psychosocial measures. The two sociodemographic variables remained significant when entered in a regression with all four psychosocial measures one at a time. Subsequently, the two sociodemographic variables were entered into a regression procedure with the four variables representing key HBM constructs that had significance of 0.200 or lower from the correlation procedures. Those that were not significant (self-efficacy, perceived risk, and fear of colonoscopy) were eliminated sequentially based on significance levels.

\section{Results}

In the final model, language and income remain as the significant sociodemographic predictors of the outcome and perceived benefits, represented by pros of colonoscopy, remains as the sole HBM key construct that is a significant predictor of colonoscopy completion (Table 3). The odds ratios (OR) indicate that those who spoke Spanish and not English were more than twice as likely as English or bilingual speakers to complete a colonoscopy (OR, 2.192; confidence interval (CI), 1.410, 3.409; $p<0.005)$. For each unit increase in household income (eight levels starting at under $\$ 10,000$ ranging to above $\$ 50,000$ ), participants were about $20 \%$ more likely to complete a colonoscopy than those with the income level immediately below them (OR, 1.218; CI, 1.106, 1.340; $p<0.005$ ). Participants with higher scores on the scale pros of colonoscopy, which represented the key construct perceived benefits, were more than one and a half times more likely to complete a colonoscopy than those with lower scores (OR, $1.535 ; \mathrm{CI}, 1.062,2.218 ; p=0.023)$. The Chi-square value for the Hosmer and Lemeshow goodness-of-fit test is 7.171 ( $8 d f$, significance $=0.518$ ), indicating strong support for the final model.

\section{Discussion}

This manuscript reports on two goals that were not previously explored in our earlier cited analyses. First, we aimed to test the ability of the HBM to predict completion of colonoscopy in order to contribute to the literature on health behavior

Table 3 Final model, odds ratios, and significance

\begin{tabular}{lll}
\hline Variables & $\begin{array}{l}\text { Odds ratio } \\
(95 \% \mathrm{CI})\end{array}$ & Significance \\
\hline $\begin{array}{l}\text { Language (speaking Spanish } \\
\text { and not English) }\end{array}$ & $2.192(1.410,3.409)$ & 0.000 \\
$\begin{array}{l}\text { Household income (higher) } \\
\text { Pros and cons-pros subscale }\end{array}$ & $1.218(1.106,1.340)$ & 0.000 \\
\hline
\end{tabular}


models in cancer screening. Second, we believe that it is clinically helpful to aggregate this sample of African Americans and Latinos/as for analytical purposes in order to approximate a sample similar to patient populations of many health care providers across the USA. Aside from efforts to ensure that patients and providers speak the same language or that quality translation is available, it is unlikely that separate interventions for Latinos/as and African Americans will be delivered to increase colonoscopy completion rates. For this reason, we believe it is useful to examine predictors of colonoscopy completion in a population that is ethnically mixed and that generally has extremely low colonoscopy completion rates, to gain an understanding of what factors may lead to completion or need special attention when implementing or providing PN services.

The results of this investigation show that, in this minority urban sample, the strongest predictors of colonoscopy completion were speaking Spanish but not English, higher household income, and higher scores on the pros of colonoscopy subscale controlling for the demographic variables age, race/ethnicity, marital status, employment status, insurance, and origin, and then the variables representing other key constructs in the HBM (perceived susceptibility, perceived barriers, and self-efficacy). Those who spoke Spanish and not English were more than twice as likely to complete a colonoscopy as those who either spoke English and not Spanish or who were bilingual in English and Spanish. For each unit increase in household income above $\$ 10,000$, participants were more than one and one fifth times more likely to complete a colonoscopy. Participants with higher endorsement of the pros of colonoscopy were one and one half times more likely to complete a colonoscopy compared with those with lower endorsement of pros of colonoscopy. The variables that were eliminated due to non-significance may be theoretically relevant but were not supported in this data set. However, since the other key HBM psychosocial factors were not present in the final model, and since the final model only explained $4.5-7.0 \%$ of the variance in outcome as explained by the model, other health behavior theories may better explain colonoscopy completion. In particular, models with predictive normative or cultural/ecological factors such as Theory of Planned Behavior [33-35] or the Behavioral Ecological Model [36, 37] may be worth exploring.

Previous research findings are mixed regarding mainstream language use and health outcomes. English proficiency has been identified as a predictor of the receipt of preventive services among Mexican Americans [38] and Latinos/as in the USA [39] and mainstream language proficiency and acculturation have been associated with higher screening behavior, use of preventive services, and acquisition of health information [40-42]. Other research has found that limited English proficiency is a greater barrier to CRC screening for men than for women [43]. The present study is consistent with research showing that language is not a barrier to cancer screening if access to care is available [44]. In the present study, monolingual Spanish speakers were assigned Spanish-speaking patient navigators with the result being that monolingual Spanish speakers had even higher completion rates than English speakers or bilingual Spanish-English speakers and the variable race/ethnicity did not remain a predictor. This finding merits further investigation. The second sociodemographic factor associated with colonoscopy completion, higher income, has been found to be predictive for colonoscopy completion $[9,45-48]$ with only rare exception [49].

Health behavior constructs have not been as thoroughly studied for colonoscopy as they have been for FOBT or flexible sigmoidoscopy [50]. However, among published studies, the construct of perceived benefits of screening for $\mathrm{CRC}$ has been relatively well examined. A descriptive review evaluating the examination of decision-making constructs within four health behavior models in studies of CRC screening found that of 26 studies which examined the construct of perceived benefits and relationship with colonoscopy, 18 found a positive relationship, with perceived benefits predicting completion, while eight found no relationship, and no study found a negative relationship. Our analysis supports previous findings that strong endorsement of perceived benefits (measured by the pros of colonoscopy subscale) predicts colonoscopy completion. The construct of selfefficacy was a later addition to some versions of the HBM. While the attention required to colonoscopy preparation would intuitively seem to require high levels of self-efficacy, our analysis did not support the inclusion of self-efficacy in the HBM for completion of colonoscopy. Neither did we find the relationships predicted by the HBM for the key constructs perceived barriers, perceived susceptibility, or knowledge. Perceived risk might be more salient in a sample that includes individuals with higher risk for CRC such as individuals with a positive family history. This suggests that, in our sample of individuals at average risk for CRC, the most important factor to emphasize in patient education efforts is the benefits to receiving a colonoscopy. Enhanced perception of the benefits of colonoscopy may help to override other concerns.

The benefits of PN have been demonstrated for various cancer conditions [51], including in achieving equivalency in time from abnormal findings on screening to diagnostic resolution among African Americans compared with whites [52, 53] and in reducing time from diagnosis to initiation of treatment among Latinas and other minorities compared with nonnavigated women and to white navigated women [54]. The benefits of navigation for African American and Latino populations diagnosed with cancer are likely to extend to $\mathrm{PN}$ for screening interventions, since ethnic minority patients tend to have lower SC rates than whites, experience more barriers to the receipt of timely screening, and tend to be diagnosed later 
in disease stage [9]. We suggest that, among African Americans and English-speaking Latino/a patients and among patients with lower incomes, benefits of colonoscopy could be more deeply explored by expanding PN to integrate elements of individualized "client-centered" counseling as is used in counseling and testing for other conditions such as HIV infection [55]. This type of enhanced "patient-centered" communication has been promoted by the National Cancer Institute [56]. We recommend efforts to reduce cost sharing for preventive screening tests, especially among those with lower incomes.

This study has several limitations. We did not use a control group, for example, of non-navigated patients. However, since many researchers have demonstrated that navigation is successful in increasing colonoscopy rates, we would submit that, at this point, it is important to implement navigation on a national level while continuing to explore how and why navigation works. While we asked the amount of participants' household income, we did not ask how many people were supported by that income. Thus, it may have been shared and may not have been an accurate estimate of financial resources. Ways in which some potentially relevant variables such as knowledge, pros and cons, and the three items used to represent perceived susceptibility were measured may not have been adequate. As utilized in this sample, the scales involved small numbers of items, had low internal reliability scores, or were developed for a population with different demographic characteristics. While we collected data on knowledge about colonoscopy, we did not attempt to measure general health literacy. Among adults 65 and older, health literacy has been associated with understanding information about CRC and taking preventive health measures including CRC screening $[57,58]$. Future studies should explore health literacy levels and acceptance of SC.

Despite these limitations, these findings are useful to consider when developing or attempting to improve PN programs. African Americans and Latinos/as who are most comfortable speaking English and any patients who have lower incomes may encounter barriers to completing a colonoscopy that are not obvious to health care providers. Such patients may need additional support to help them consider how to overcome barriers to completing a colonoscopy procedure. We suggest that benefits of SC should be emphasized in patient education efforts and that benefits could be usefully explored by expanding the usual format of PN to integrate elements of individualized patient-centered counseling as described above. Among those patients who were navigated in this study but did not complete colonoscopy, exploratory interviews could elucidate their views and perceptions of the benefits of SC and the challenges they experienced in contemplating or attempting to obtain a colonoscopy. One such study, with 16 of the African American participants who did not complete a colonoscopy [59], identified barriers on three levels: intrapersonal-level factors such as fear/anxiety about the colonoscopy procedure, lack of knowledge of CRC, and believing that cancer leads to death; interpersonal-level factors including inadequate physician explanation of colonoscopy and PN issues; and community-level factors, such as social burden and life circumstances. The barriers identified on the intrapersonal and interpersonal levels could be addressed through enhanced education and counseling such as that suggested above.

Acknowledgments Thanks to the recruiters, patient navigators, data managers, and Mount Sinai Hospital Internal Medicine Associate physicians and staff who contributed to this project. We especially thank the patient participants.

Grant Support The research reported in this analysis was supported by the National Cancer Institute, grant number CA 120658 and the Icahn School of Medicine at Mount Sinai. Colonoscopy for uninsured patients was funded by the American Cancer Society. This analysis was partially supported by a National Institutes of Health Postdoctoral Fellowship in Cancer Prevention and Control, grant number CA 81137. Jamilia Sly, $\mathrm{PhD}$ was supported by a Postdoctoral Fellowship, PF-13-018-01-CPPB from the American Cancer Society.

Conflict of Interest Debra J. Pelto, Jamilia R. Sly, Gary Winkel, William Redd, Hayley S. Thompson, Steven Itzkowitz, and Lina Jandorf declare that they have no conflict of interest.

Informed Consent All procedures followed were in accordance with the ethical standards of the responsible committee on human experimentation (institutional and national) and with the Helsinki Declaration of 1975, as revised in 2000 (5). Informed consent was obtained from all patients for being included in the study.

\section{References}

1. U.S. Cancer Statistics Working Group. United States cancer statistics: 1999-2009 incidence and mortality web-based report. 2013. Available from: http://apps.nccd.cdc.gov/uscs/ cancersbyraceandethnicity.aspx.

2. Winawer SJ et al. Colorectal cancer screening: clinical guidelines and rationale. Gastroenterology. 1997;112:594-642.

3. Levin B et al. Screening and surveillance for the early detection of colorectal cancer and adenomatous polyps, 2008: a joint guideline from the American Cancer Society, the US Multi-Society Task Force on Colorectal Cancer, and the American College of Radiology* $\uparrow$. CA Cancer J Clin. 2008;58(3):130-60.

4. Rex DK et al. American College of Gastroenterology guidelines for colorectal cancer screening 2008. Am J Gastroenterol. 2009;104: 739-50.

5. U.S. Department of Health and Human Services and Office of Disease Prevention and Health Promotion. Healthy people 2020. Available from: http://www.healthypeople.gov/2020/ topicsobjectives $2020 /$ objectiveslist.aspx?topicId $=5$. Accessed 22 Aug 2013

6. National Center for Chronic Disease Prevention and Health Promotion and Division of Cancer Prevention and Control, Colorectal cancer tests save lives, in Vital Signs. 2013, Centers for Disease Control and Prevention, Atlanta. 
7. American Cancer Society. Colorectal cancer facts and figures. 20112013. Atlanta: American Cancer Society; 2011.

8. Klabunde CN. Vital signs: colorectal cancer screening test useUnited States, 2012, in Morbidity and Mortality Weekly Report. Atlanta: Centers for Disease Control and Prevention; 2013. p. 881-8.

9. Shapiro JA et al. Patterns of colorectal cancer test use, including CT colonography, in the 2010 National Health Interview Survey. Cancer Epidemiol Biomark Prev. 2012;21(6):895-904.

10. Behavioral Risk Factor Surveillance System, Colorectal cancer screening: New York State adults 2010, in BRFSS Brief. 2012, Bureau of Chronic Disease Evaluation and Research, Albany.

11. U.S. Census Bureau, American Fact Finder: selected economic characteristics, 2008-2012 American Community Survey 5-year estimates.

12. U.S. Census Bureau, Table 1. Percent of households reporting consumer durables, for householders 15 years and older, by selected characteristics: 2011. Survey of Income and Program Participation, 2008 Panel, Wave 9. 2013

13. Altekruse S, et al. SEER cancer statistics review 1975-2007, based on November 2009 SEER data submission. 2010. Available from: http://seer.cancer.gov/csr/1975-2007/.

14. Nash D et al. Evaluation of an intervention to increase screening colonoscopy in an urban public hospital setting. J Urban Health. 2006;83(2):231-43.

15. Jandorf $L$ et al. Implementation of culturally targeted patient navigation system for screening colonoscopy in a direct referral system. Health Educ Res. 2013;28(5):803-15.

16. Chen LA et al. A program to enhance completion of screening colonoscopy among urban minorities. Clin Gastroenterol Hepatol. 2008;6(4):443-50.

17. Jandorf $\mathrm{L}$ et al. Culturally targeted patient navigation for increasing African Americans' adherence to screening colonoscopy: a randomized clinical trial. Cancer Epidemiol Biomark Prev. 2013;22(9): 1577-87.

18. Braschi $\mathrm{CD}$, et al. Increasing colonoscopy screening for Latino Americans through a patient navigation model: a randomized clinical trial. Journal of Immigrant and Minority Health, 2013: p. 1-7.

19. Denberg TD et al. Predictors of nonadherence to screening colonoscopy. J Gen Intern Med. 2005;20(11):989-95.

20. Diaz JA et al. Effect of language on colorectal cancer screening among Latinos and non-Latinos. Cancer Epidemiol Biomark Prev. 2008;17(8):2169-73.

21. Dorn SD et al. Impact of the 2008-2009 economic recession on screening colonoscopy utilization among the insured. Clin Gastroenterol Hepatol. 2012;10(3):278-84.

22. Gupta M, Holub JL, Eisen G. Do indication and demographics for colonoscopy affect completion? A large national database evaluation. Eur J Gastroenterol Hepatol. 2010;22(5):620-7.

23. Gorin SS, Heck JE. Cancer screening among Latino subgroups in the United States. Prev Med. 2005;40:515-26.

24. Holt CL et al. Spiritually based intervention to increase colorectal cancer screening among African Americans: screening and theorybased outcomes from a randomized trial. Health Educ Behav. 2013;40(4):458-68.

25. Janz NK et al. Colorectal cancer screening attitudes and behavior: a population-based study. Prev Med. 2003;37(6):627-34.

26. Rawl SM et al. Computer-delivered tailored intervention improves colon cancer screening knowledge and health beliefs of AfricanAmericans. Health Educ Res. 2012;27(5):868-85.

27. Salz $\mathrm{T}$ et al. Association of health beliefs and colonoscopy use among survivors of colorectal cancer. J Cancer Surviv. 2009;3(4):193-201.

28. Wong RK, et al. Gender differences in predictors of colorectal cancer screening uptake: a national cross sectional study based on the Health Belief Model. BMC Public Health, 2013. 13.
29. Cantor D. Health Information National Trends Survey 2005 (HINTS 2005) final report, prepared for National Cancer Institute. Rockville: Westat; 2005.

30. Manne $\mathrm{S}$ et al. Correlates of colorectal cancer screening compliance and stage of adoption among siblings of individuals with early onset colorectal cancer. Health Psychol. 2002;21(1):3-15.

31. Manne SL et al. A randomized trial of generic versus tailored interventions to increase colorectal cancer screening among intermediate risk siblings. Ann Behav Med. 2009;37(2):207-17.

32. Champion V, Skinner CS, Menon U. Development of a self-efficacy scale for mammography. Res Nurs Health. 2005;28(4):329-36.

33. Ajzen I. The Theory of Planned Behavior. Organ Behav Hum Decis Process. 1991;50(2):179-211.

34. Ajzen I. Perceived behavioral control, self-efficacy, locus of control, and the Theory of Planned Behavior. J Appl Soc Psychol. 2002;32: 665-83.

35. Ajzen I, Manstead ASR. Changing health-related behaviours: an approach based on the Theory of Planned Behaviour. In: van den Bos K, editor. The scope of social psychology: theory and applications. New York: Psychology Press; 2007.

36. Hovell M, Wahlgren D, Adams M. The logical and empirical basis for the Behavioral Ecological Model. In: DiClemente RJ, Crosby RA, Kegler MC, editors. Emerging theories in health promotion and practice. San Francisco: Jossey-Bass; 2009. p. 415-49.

37. Hovell MF, Wahlgren DR, Gehrman CA. The Behavioral Ecological Model: integrating public health and behavioral science. In: DiClemente RJ, Crosby RA, Kegler MC, editors. Emerging theories in health promotion practice and research: strategies for improving public health. San Francisco: Jossey-Bass; 2002.

38. Suarez L, Pulley L. Comparing acculturation scales and their relationship to cancer screening among older Mexican-American women. J Natl Cancer Inst Monogr. 1995;18:41-7.

39. Dubard CA, Gizlice Z. Language spoken and differences in health status, access to care, and receipt of preventive services among US Hispanics. Am J Public Health. 2008;98(11):2021-8.

40. Echeverria SE, Carrasquillo O. The roles of citizenship status, acculturation, and health insurance in breast and cervical cancer screening among immigrant women. Med Care. 2006;44(8):788-92.

41. Afable-Munsuz A et al. Acculturation and colorectal cancer screening among older Latino adults: differential associations by national origin. J Gen Intern Med. 2009;24(8):963-70.

42. Johnson-Kozlow M. Colorectal cancer screening of Californian adults of Mexican origin as a function of acculturation. J Immigr Minor Health. 2010;12(4):454-61.

43. Diaz JA et al. Colorectal cancer screening: language is a greater barrier for Latino men than Latino women. J Immigr Minor Health. 2013;15(3):472-5.

44. Zambrana RE et al. Use of cancer screening practices by Hispanic women: analyses by subgroup. Prev Med. 1999;29:466-77.

45. Daly JM, Xu Y, Levy BT. Patients whose physicians recommend colonoscopy and those who follow through. J Prim Care Community Health. 2013;4(2):83-94.

46. Menon $U$ et al. Correlates of colorectal cancer screening among South Asian immigrants in the United States. Cancer Nurs. 2014;37(1):E19-27.

47. Oliver JS et al. Disparities in colorectal cancer screening behaviors: implications for African American men. Gastroenterol Nurs. 2012;35(2):93-8.

48. Richards CA et al. Increased screening colonoscopy rates and reduced racial disparities in the New York Citywide Campaign: an urban model. Am J Gastroenterol. 2011;106(11):1880-6.

49. Basch $\mathrm{CH}$ et al. Distinguishing factors for asymptomatic colonoscopy screening. J Cancer Educ. 2012;27(3):521-5.

50. Kiviniemi MT et al. Individual-level factors in colorectal cancer screening: a review of the literature on the relation of individual- 
level health behavior constructs and screening behavior. PsychoOncology. 2011;20(10):1023-33.

51. Hoffman HJ et al. Patient navigation significantly reduces delays in breast cancer diagnosis in the District of Columbia. Cancer Epidemiol Biomark Prev. 2012;21(10):1655-63.

52. Paskett ED et al. The Ohio Patient Navigation Research Program: does the American Cancer Society patient navigation model improve time to resolution in patients with abnormal screening tests? Cancer Epidemiol Biomark Prev. 2012;21(10):1620-8.

53. Raich $\mathrm{PC}$ et al. Patient navigation improves cancer diagnostic resolution: an individually randomized clinical trial in an underserved population. Cancer Epidemiol Biomark Prev. 2012;21(10):1629-38.

54. Dudley DJ et al. Beneficial effects of a combined navigator/promotora approach for Hispanic women diagnosed with breast abnormalities. Cancer Epidemiol Biomark Prev. 2012;21(10):1639-44.
55. Sheon N. Theory and practice of client-centered counseling and testing, in HIV InSite knowledge base chapter. 2004.

56. Epstein RM, Street RLJ. Patient-centered communication in cancer care: promoting healing and reducing suffering. Bethesda: National Cancer Institute; 2007.

57. White S, Chen J, Atchison R. Relationship of preventive health practices and health literacy: a national study. Am J Health Behav. 2008;32(3):227-42.

58. Todd L, Hoffman-Goetz L. Predicting health literacy among Englishas-a-Second-Language older Chinese immigrant women to Canada: comprehension of colon cancer prevention information. J Cancer Educ. 2011;26(2):326-32.

59. Sly JR et al. Identifying barriers to colonoscopy screening for nonadherent African American participants in a patient navigation intervention. Health Educ Behav. 2013;40(4):449-57. 